$\mathrm{Cl}$ oni ng and nucl eot i de sequence of the maj or capsi d protei ns of Lact obaci I I us bact eri ophage $\Phi$ gl e

\begin{tabular}{|l|l|}
\hline 著者 & $\begin{array}{l}\text { KAK KAWA Naki ko, OK Nasaya, TADOKORO } \\
\text { H say uki, NAKAMRA Shogo, TAKETO Aki ra, } \\
\text { KODAl RA Ken- I chi }\end{array}$ \\
\hline $\begin{array}{l}\text { j our nal or } \\
\text { publ i cat i on t i t l e }\end{array}$ & Gene - Anst er dam \\
\hline vol une & 175 \\
\hline number & $1-2$ \\
\hline page r ange & $157-165$ \\
\hline year & $1996-10$ \\
\hline URL & ht t p: //hdl . handl e. net /10098/1621 \\
\hline
\end{tabular}




\title{
Cloning and nucleotide sequence of the major capsid proteins of Lactobacillus bacteriophage $\phi$ gle
}

\author{
Makiko Kakikawa ${ }^{a}$, Masaya Oki ${ }^{a}$, Hisayuki Tadokoro ${ }^{a}$, Shogo Nakamura ${ }^{b}$, \\ Akira Taketo $^{c}$, Ken-Ichi Kodaira ${ }^{\text {a, }}$ \\ ${ }^{a}$ Molecular Biology Group, Chemical and Biochemical Engineering. Faculty of Engineering, Toyama University, 3190, Gofuku, \\ Toyama, Toyama 930, Japan \\ ${ }^{\mathrm{b}}$ Department of Environmental Biology and Chemistry, Faculty of Science, Toyama University, 3190, Gofuku, \\ Toyama, Toyama 930, Japan \\ ${ }^{\mathrm{c}}$ Department of Biochemistry I, Fukui Medical School, Matsuoka, Fukui, Fukui 910-11, Japan
}

\begin{abstract}
Bacteriophage $\phi g l e$ was induced from a lysogenic Lactobacillus strain Gle. $\phi$ gle genome is double-stranded DNA of approximately 42.5 kilo-base $(\mathrm{kb})$ pairs. SDS poly-acrylamide gel electrophoresis demonstrated that the phage particles contain 4 major structural (capsid) proteins, gpB, gpG, gpO, and gpP, whose molecular weights (MW) are estimated to be 64, 43, 29 and 26 kilodaltons $(\mathrm{kDa})$, respectively. More than 16 minor proteins ranging from 113 to $9.6 \mathrm{kDa}$ were also detected. The genes for the major capsid proteins were cloned and each DNA sequence was determined. $\mathrm{N}$-terminal amino acid alignments determined by protein sequencing completely coincided with those deduced from the nucleotide sequences.
\end{abstract}

Keywords: Temperate phage; Lactobacillus; Capsid protein; Phage structural gene; Protein sequence; DNA sequence

\section{Introduction}

Lysogeny among an abundance of lactic acid bacteria has been recognized widely (Davidson et al., 1990). On the analogy of Escherichia coli lambda system (Campbell, 1994), temperate phages of lactic acid bacteria, such as Lactobacillus and Lactococcus species, have been regarded as valuable genetic tools of gene transfer (transduction) and cloning in these industrially and medically important genera (Lillehaug and Birkeland, 1993; Raya et al., 1992).

In contrast to coliphages, molecular details of the temperate phages of lactic acid bacteria are still unclear: host-range, gene-organization, replication, classification, evolution, and so on (Relano et al. 1987; Davidson et al., 1990; Raya et al., 1992).

In the genus Lactobacillus, three temperate phages, $\phi$ adh from gasseri ADH (Raya et al., 1989, 1992), $\phi F S W$ from casei (Shimizu-Kadota and Tsuchida, 1984) and PL-1 from casei ATCC 27092 (Nakashima et al., 1994) have been so far characterized extensively. These results have demonstrated that they are significantly different in the structures of phage particle and genome, and there exist hard barriers to industrial applications of Lactobacillus temperate phages.

More recently, we have identified a bacteriophage, designated $\phi g \mathrm{gle}$, which was induced from a lysogenic Lactobacillus strain Gle in a fermented plant in Japan. Phage $\phi$ gle considerably differs from other Lactobacillus phages, $\phi$ adh, $\phi F S W$, and PL-1 in genome size and morphology.

In this study, we electrophoretically analyzed $\phi$ gle capsid proteins, and sequenced $\mathrm{N}$-terminal aa alignments of the 4 major proteins, gpB, gpG, gpO and gpP, and determined DNA sequences of the $\phi$ gle genome encoding these 4 proteins.

These results afford an important clue to further studies of molecular biology of Lactobacillus phages.

\section{Materials and methods}

\subsection{Bacteria, phage, and plasmids}

The lysogenic Lactobacillus strain Gle was originally isolated in our laboratory in a fermented plant (unpub- 
lished result). The Gle cells were grown in GYP (Okada et al., 1986) or M17 (Terzaghi and Sandine, 1975) broth at $30^{\circ} \mathrm{C}$. Development of bacteriophage $\phi$ gle was induced from Gle by mitomycin C (MMC), and the phage particles were then purified as follows. When the $A_{660}$ of the culture (GYP broth) had reached 0.25 , MMC was added to a final concentration of $5.0 \mu \mathrm{g} / \mathrm{ml}$. After incubation for further $20 \mathrm{~min}$ at $30^{\circ} \mathrm{C}$, the cells were harvested by centrifugation, suspended in fresh medium, and incubated at $30^{\circ} \mathrm{C}$. After lysis, the cell lysate was centrifuged at $5000 \times g$ for $15 \mathrm{~min}$. Liberated phages in the supernatant were purified by the method of Yamamoto et al. (1970): phage particles were concentrated with $10 \%$ polyethylene glycol 6000 and $0.5 \mathrm{M} \mathrm{NaCl}$, and then purified by $\mathrm{CsCl}$ step and equilibrium gradient centrifugations. Phages thus banded were collected and dialyzed against phage buffer containing $20 \mathrm{mM}$ Tris. $\mathrm{HCl}$ ( $\mathrm{pH} 7.5$ ), $0.1 \mathrm{M} \mathrm{NaCl}$, and $0.001 \mathrm{M} \mathrm{MgSO}_{4}$. Cells of E. coli XL1-blue were grown in $\mathrm{LB}$ or $2 \mathrm{YT}$ broth, and the E. coli vector plasmids (pUC18, pUC19, pUC118 and pUC119) were prepared by the method of Sambrook et al. (1989).

\subsection{Electron microscopy}

Phages were applied on carbon-coated grids (200 mesh; Oken Shoji Co., Ltd., Tokyo) and negatively stained with $1 \%$ uranyl acetate. Micrographs were taken with a JEOL 100SX electron microscope at $80 \mathrm{kV}$.

\subsection{Analysis of phage proteins}

For detection of phage proteins, the purified phage particles were subjected to electrophoresis on $12 \%$ SDS polyacrylamide slab gels (SDS-PAGE) together with authentic marker proteins as described by Kodaira et al. (1984). The electrophoresed gel was stained by Coomassie brilliant blue (CBB) R-250, and then subjected to silver staining. The bands stained with $\mathrm{CBB}$ were scanned using an imaging densitometer (BIO-RAD model GS-700). Two-dimensional (isoelectric focusingSDS polyacrylamide slab gel) electrophoresis was performed as described previously by Tomoda et al. (1984). The first isoelectric gel contained ampholine covering $\mathrm{pH}$ from 3.5 to 10 . The foregoing $12 \%$ polyacrylamide containing $0.1 \%$ SDS was used as the seconddimensional gel. For amino-acid sequencing, the purified $\phi$ gle particles were subjected to $12 \%$ SDS-PAGE and then electroblotted to a PVDF membrane (Perkin Elmer Applied Biosystems division). After transfer, the PVDF membrane was stained with CBB R-250. The protein bands were excised from the CBB-stained PVDF membrane, and then subjected to $\mathrm{N}$-terminal aa sequence analysis using an Applied Biosystems Procise or 476A sequencer.

\subsection{Analysis of phage $D N A$}

Southern blot hybridization was performed according to a procedure described by Hosono et al. (1992). DNA was electrophoresed on $1 \%$ agarose gel, followed by transfer to a positively charged nylon membrane (Boehringer Mannheim). After transfer, the membrane was baked at $121{ }^{\circ} \mathrm{C}$ for $15 \mathrm{~min}$. Probes were labeled with digoxigenin-11-dUTP, and hybridizations were performed according to the supplier (Boehringer Mannheim). ${ }^{32}$ P-Labeled probes were prepared by nick translation (Kodaira et al., 1994a). Cloning of $\phi g l e$ DNA was carried out essentially as described by Kodaira et al. (1992). Hybrid DNAs between restriction DNA fragment of $\phi$ gle and $E$. coli vector plasmid were introduced into $E$. coli XL1-blue by $\mathrm{Ca}^{2+}$-dependent transformation or electroporation (Taketo, 1988). For genome analysis, several series of restriction library from $\phi$ gle DNA in E. coli plasmids (pUC series) were constructed using restriction enzymes. For DNA sequencing, various deletion clones were constructed from the libraries by Bal31 nuclease digestion (Kodaira et al., 1994b). The DNA sequence was determined by the chain termination method (Sanger et al., 1977). All other procedures were performed as described previously by Kodaira et al. (1992).

\subsection{Enzymes and biochemicals}

Restriction enzymes, phage T4 DNA ligase, and alkaline phosphatase (calf intestine) were purchased from Takara Shuzo (Kyoto) and Nippon Gene (Toyama). Buffers for each enzymes were as recommended by the manufacturers.

$\left[\alpha^{32} \mathrm{P}\right] \mathrm{dCTP}$ was from NEN. All other materials were described previously by Kodaira et al. (1992).

\section{Results and discussion}

\subsection{Structure of $\phi$ gle phage particle}

Structure of the $\phi$ gle phage particle was analyzed by electron microscopy. As presented in Fig. 1, 申gle has (i) an isometric and hexagonal head (63 $\mathrm{nm}$ in diameter), (ii) a remarkably long noncontractile and flexible tail $(260 \mathrm{~nm}$ in length and $10 \mathrm{~nm}$ in width) with regularly spaced transversal striations, and (iii) a complicated stacked-baseplate (from 45 to $24 \mathrm{~nm}$ in diameter) ending in several short fibers (12 nm long) (see Fig. 4B and C).

Phage $\phi g l e$ thus exhibited a morphotype that has not been previously reported for Lactobacillus and Lactococcus phages. 


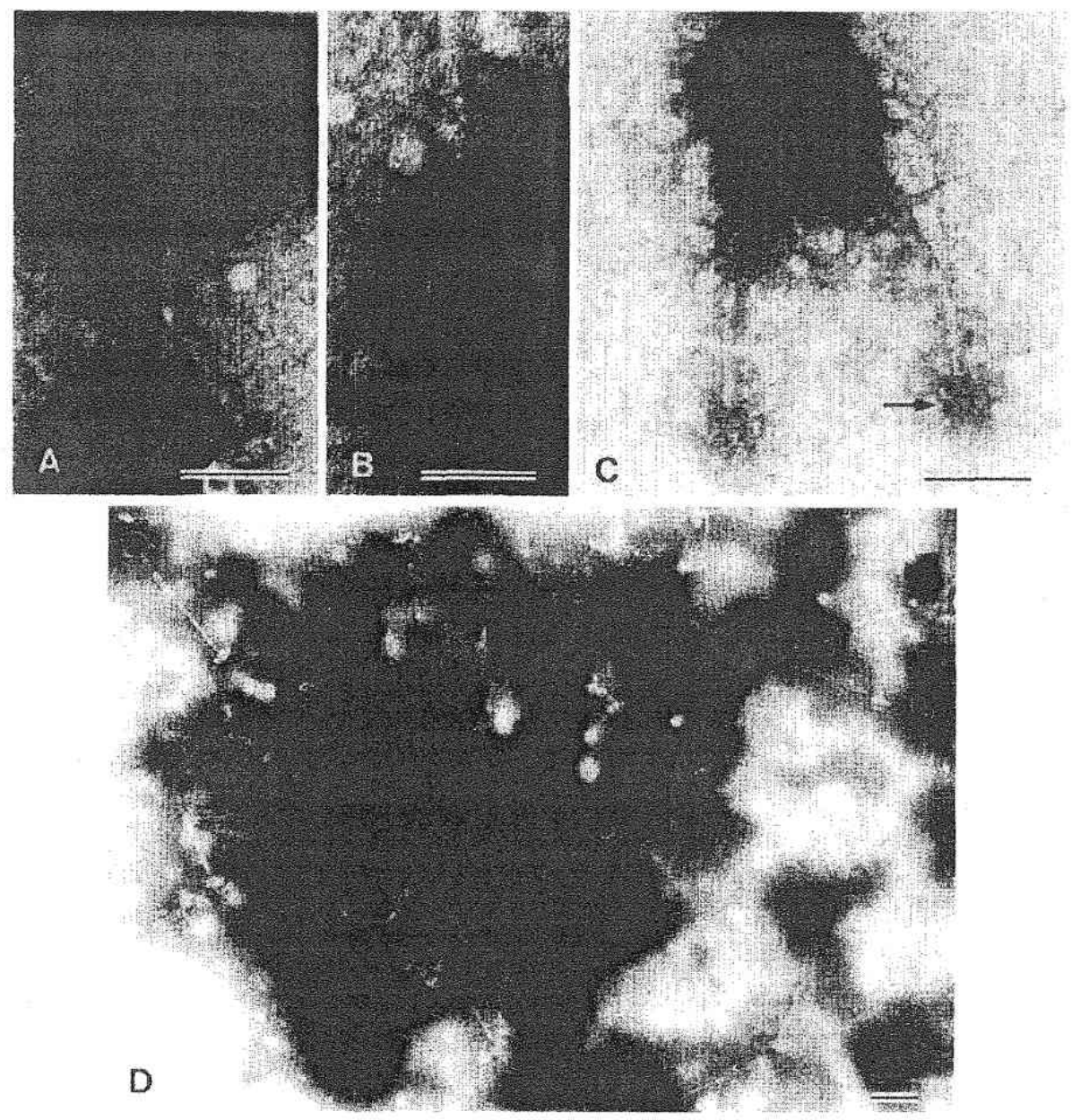

Fig. 1. Electron micrograph of $\phi g l e$ virion particles. Phages were negatively stained with uranyl acetate. (A) $\phi g l e$ filtered $(0.45 \mu \mathrm{m})$ from cell lysates; (B) same as (A), magnified two stacked base plates and short fibers; (C) same as (A), magnified two stacked base plates from the bottom; (D) $\phi$ gle purified by $\mathrm{CsCl}$ centrifugation. Bars: $100 \mathrm{~nm}$ (A, C, D); $50 \mathrm{~nm}$ (B).

\subsection{Analysis of $\phi g l e$ capsid proteins}

Purified $\phi$ gle particles were disrupted by heating in the denaturing buffer containing SDS and mercaptoethanol (see Section Materials and methods), and subjected to $12 \%$ SDS-PAGE together with authentic marker proteins. Staining the electrophoresed gel with CBB R-250 revealed that $\phi$ gle particles are composed of 4 major capsid proteins, referred to as $\mathrm{gpB}$, gpG, gpO and $\mathrm{gpP}$, whose molecular weights are estimated to be $64,43,29$ and $26 \mathrm{kDa}$, respectively (Fig. 2A, lane 2); the relative abundance estimated by densitometric analysis is $1.0(\mathrm{gpB}), 4.0(\mathrm{gpG}), 0.5(\mathrm{gpO})$ and $2.6(\mathrm{gpP})$. In addition to these 4 major proteins, at least 16 minor proteins ranging from 113 to $9.6 \mathrm{kDa}$ were detected after silver staining (Fig. 2A, lane 3).

Upon two-dimensional electrophoresis (see Section Materials and methods), each of the 4 proteins, gpB, $\mathrm{gpG}, \mathrm{gpO}$ and $\mathrm{gpP}$, gave a single spot on a second silver-stained gel (Fig. 2B). The 3 proteins gpB, gpG and
gpP were significantly acidic, whose isoelectric points $(\mathrm{p} I)$ were estimatëd to be approximately 5.0 , whereas the gpO protein was neutral ( $\mathrm{p} I$, approximately 6.5 ).

These results suggested that $\phi$ gle differs from lactic acid phages reported so far (see above) in capsid protein and genome structure (see below).

We determined $\mathrm{N}$-terminal aa sequences of the 4 major proteins, gpB, gpG, gpO and gpP, by a method of protein-blotting to a PVDF sequencing membrane (see Section Materials and methods). Their aa alignments are presented in Table 1: the first methionine was absent in the 3 proteins $g p G, g p O$ and $g p P$.

\subsection{Cloning and DNA sequence of the $\phi g l e$ genes coding for the major proteins}

Fig. 3 shows a physical map of the $\phi$ gle genome DNA composed of approximately $42.5 \mathrm{~kb}$. The $\phi g l e$ DNA is circularly permuted; whether $\phi$ gle belongs to pac or cos type is now under investigation. 
To map structural genes for the 4 major capsid proteins $\mathrm{gpB}, \mathrm{gpG}, \mathrm{gpO}$ and $\mathrm{gpP}$, mixed oligonucleotide probes were prepared based on their N-terminal aa alignments (see Table 1): for example, 5'-AA(A/G)TT(T/C) AA (A/G) ATGAA (T/C) TA (T/C) AA (A/G) AA-

\section{(A)}
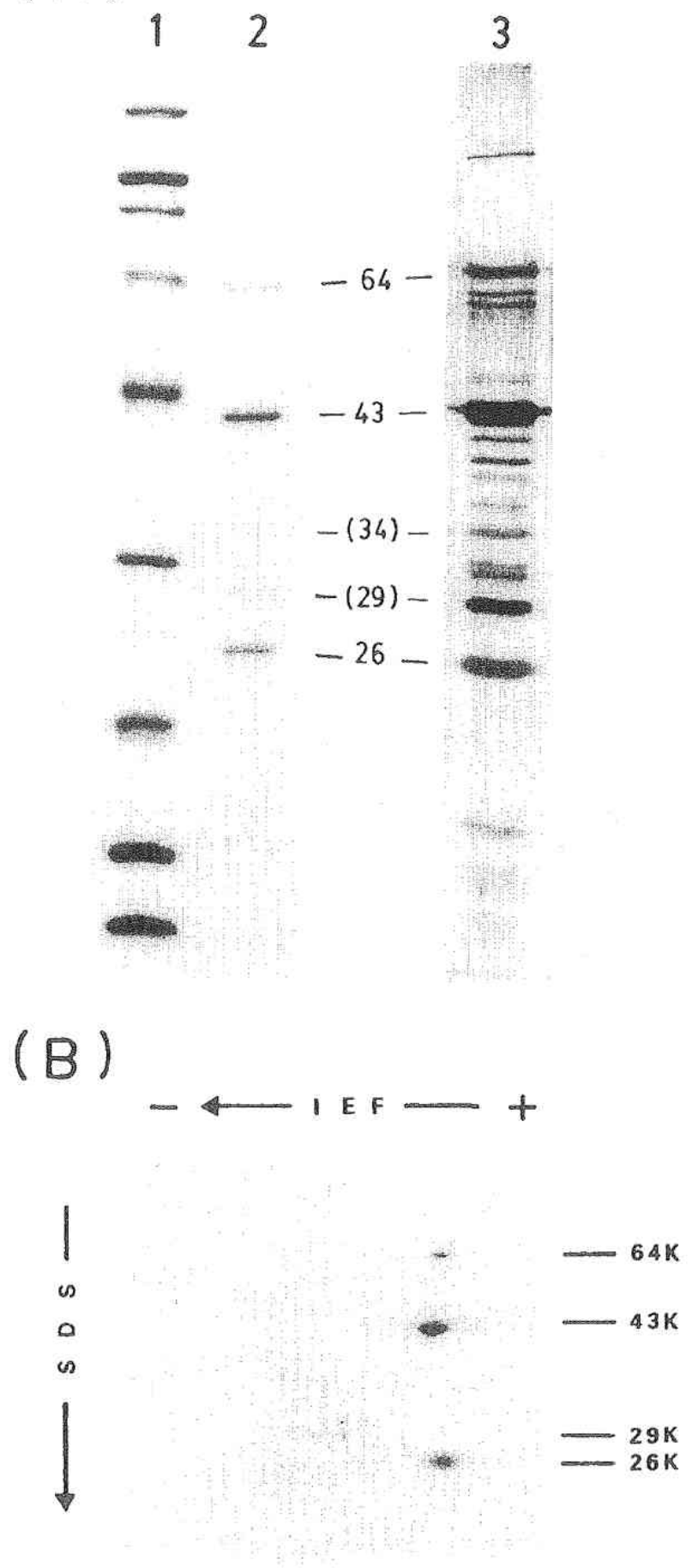

(T/C)-3' for gpP. By Southern blot experiment (data not shown), each of the probes for gpB, gpG, gpO and gpP hybridized to a single unique restriction fragment: $5^{\prime}$ regions of gene $\mathrm{B}$ (for $\mathrm{gpB}$ ), gene $\mathrm{G}$ ( $\mathrm{gpG}$ ), gene $\mathrm{O}(\mathrm{gpO})$ and gene $\mathbf{P}(\mathrm{gpP})$ are located in $2.5 \mathrm{~kb}$ of an EcoRI fragment, $4.1 \mathrm{~kb}$ of a SalI/EcoRI fragment, $1.8 \mathrm{~kb}$ of an EcoRI fragment and $4.8 \mathrm{~kb}$ of a SalI fragment, respectively (see Fig. 3).

Based on the Southern blot experiments, we sequenced 3 regions of $\phi$ gle genome (see Fig. 3): (1) $1.5 \mathrm{~kb}$ from HindIII to EcoRV (containing gene G), (2) $1.0 \mathrm{~kb}$ from HinclI to EcoO109I (gene P), and (3) $3.6 \mathrm{~kb}$ from EcoRV to $\mathrm{XbaI}$ (genes $\mathrm{B}$ and $\mathrm{O}$ ).

The sequencing analysis revealed the expected 4 genes, $\mathrm{G}, \mathrm{P}, \mathrm{B}$ and $\mathrm{O}$, in addition to 6 truncated open reading frames (ORF): RorfU1, RorfU2, RorfU3, RorfU4, RorfU5 and RorfU6. Fig. 4 shows the DNA sequence of these genes and ORFs, together with their a alignment. They are encoded on one strand, referred to as R-strand, whereas, no ORF of significant length could be found in the complementary strand, referred to as L-strand. The 4 genes (G, P, B and $\mathrm{O}$ ) and 3 ORFs (RorfU2, RorfU4 and RorfU6) are preceded by a potential ribosome binding sequence (see Table 2), in good agreement with those of several Lactobacillus (5'-AGGAGG-3'; Pouwel and Leer, 1993) and Lactococcus (5'-AGAAAGGAGGT-3'; Ludwig et al., 1985; Schouler et al., 1994) genes.

In the 4 major capsid proteins, gpG, gpP, gpB and gpO, N-terminal aa alignments predicted by the DNA sequence were identical to those determined by the protein sequence (Table 1). These results confirmed that the genes $\mathrm{B}, \mathrm{G}, \mathrm{O}$ and $\mathrm{P}$ are structural genes for $\mathrm{gpB}$, $\mathrm{gpG}, \mathrm{gpO}$ and $\mathrm{gpP}$, respectively, and suggested that like the major phage protein gpE of coliphage lambda (Georgopoulos et al., 1983), there is no cleavage of a signal peptide from each $\phi$ gle capsid protein, prior to or during phage capsid formation.

In the 3 proteins gpG, gpO and gpP, the $\mathrm{N}$-terminal methionine was deleted probably by posttranslational processing (Table 1); the result agrees with the rule that the N-terminal methionine is generally processed when the second aa residue is alanine (Ben-Bassat and Bauer, 1987).

Fig. 2. Proteins of $\phi g l e$ phage particles. (A) Phage particles disrupted by SDS and mercaptoethanol were analyzed on a SDS polyacrylamide slab gel. Phage proteins were stained with Coomassie brilliant blue R-250 (lane 2) and then subjected to silver staining (lane 3). Lane 1, authentic marker proteins: myosin $(200 \mathrm{kDa}), \quad \beta$-galactosidase $(116.3 \mathrm{kDa})$, phosphorylase b $(97.4 \mathrm{kDa})$, bovine serum albumin $(66.2 \mathrm{kDa})$, ovalbmin $(45 \mathrm{kDa})$, carbonic anhydrase $(31 \mathrm{kDa})$, soybean trypsin inhibitor $(21.5 \mathrm{kDa})$, lysozyme $(14.4 \mathrm{kDa})$, and aprotinin $(6.5 \mathrm{kDa})$. (B) Phage particles denatured as in (A) were subjected to two-dimensional electrophoresis: first, on isoelectric focusing gel (IEF); second, on SDS gel. After electrophoresis, phage proteins were visualized by staining with Coomassie brilliant blue R-250. 
TABLE 1

Properties of the four major structural proteins of $\phi$ gle phage particle

\begin{tabular}{|c|c|c|}
\hline Protein & Molecular weight $t^{\mathrm{a}}$ & $\mathrm{N}$-terminal amino acid sequence ${ }^{\mathrm{b}}$ \\
\hline $\mathrm{gpB}$ & 64.0 & MQTLTYVIGQDRRTLVKDIINFKIDF................ \\
\hline gpG & 43.0 & AETHLSDLIVPEVFGNYVVNQIIKTNRFVQSGILT.... \\
\hline gpO & 29.0 & ANIVDKTNQIGRKTTELAANMIPA...................... \\
\hline $\mathrm{gpP}$ & 26.0 & AKFKMNYKNVFEIDTTGSQDPQDTXKAWFVPLAAXI... \\
\hline
\end{tabular}

- Molecular weights of the proteins were estimated from SDS-PAGE (Fig. 1A).

${ }^{b} \mathrm{~N}$-terminal amino acid sequence was determined by a method of protein-blotting to a PVDF sequencing membrane (see Section Materials and methods).

$\mathrm{x}$, undetermined residue.

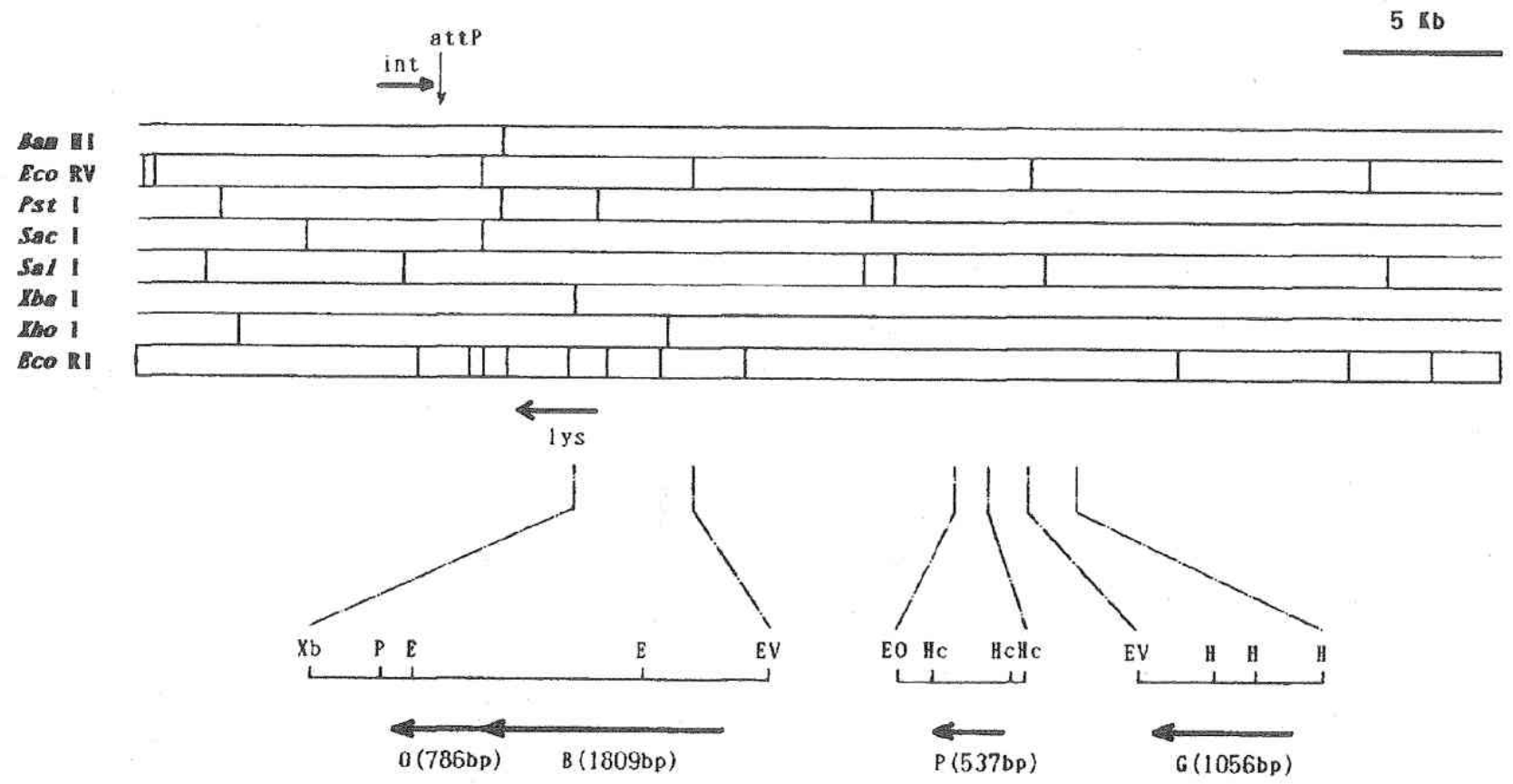

Fig. 3. Physical map of $\phi$ gle genome. Restriction physical map is linearized at one site of EcoRI. Locations of the $1.5 \mathrm{~kb}$ from $H i n$ dIII to EcoRV, the $1.0 \mathrm{~kb}$ from HincII to EcoO109I, and the $3.6 \mathrm{~kb}$ from $E c o \mathrm{RV}$ to $\mathrm{Xbal}$ are enlarged, and the genes $\mathrm{G}, \mathrm{P}, \mathrm{B}$ and $\mathrm{O}$ with their sizes and locations are indicated. E, EcoRI; EO, EcoO109I; EV, EcoRV, H, HindIII; Hc, HincII; P, PstI; Xb, XbaI. Int encodes the phage integrase, attP is the sitc of recombination with the host chromosome, and Lys encodes the phage lysin (unpublished result).

The 3 proteins gpB, gpG and gpP contain an high molar percentage of acidic aa residues, and their $\mathrm{pI}$ points were calculated as $4.75,4.85$ and 4.70 , respectively, which were in good agreement with those estimated from two-dimensional SDS-PAGE (Fig. 2B).

As shown Fig. 4A, gpG is encoded from nucleotide (nt) position 263 to 1318 , and composed of 350 aa residues; its MW was calculated to be $37.6 \mathrm{kDa}$, which is slightly smaller than that $(43.0 \mathrm{kDa})$ predicted from SDS-PAGE (Fig. 1A). In Lactococcus phage F4-1, Kim and Batt (1991) reported that proteins with low $\mathrm{p} I$ points migrate slower on SDS-PAGE.

Immediately downstream of the putative ribosome binding site (5'-AAAAAGGAGG-3') for gpG, an inverted repeat of 5 bases $\left(5^{\prime}\right.$-GCCAT- $\left.3^{\prime}\right)$ was detected (see Fig. 4A); it can form a stem-loop secondary struc- ture, which may play a role in transcriptional regulation. Two truncated ORFs RorfU1 and RorfU2 were located upstream and downstream of gene $G$, respectively. RorfU1 is separated from gene $\mathrm{G}$ by 16 bases, and the stop codon (TAA) of RorfU1 overlaps the ribosome binding site of gene $\mathrm{G}$. Between gene $\mathrm{G}$ and RorfU2, an intergenic space consisting of 23 bases exists, which contains the ribosome binding site of RorfU2 (5'-GGAAGT-3'), but no possible secondary structure.

Gene P is located approximately $1.6 \mathrm{~kb}$ downstream of gene G (Fig. 3), and is positioned from nt 190 to 726 (Fig. 3B). Like gene $G$, gene $P$ encodes the acidic protein of 177 aa residues, whose calculated mass is $18.8 \mathrm{kDa}$, and is smaller than that $(26.0 \mathrm{kDa})$ estimated from SDSPAGE (Fig. 2A). Directly downstream of gene P, a stemloop structure was detected, whose stem is composed of 


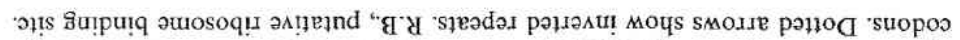

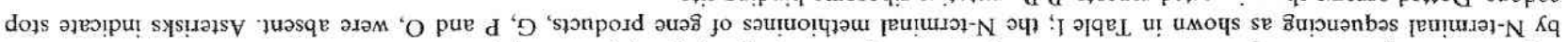

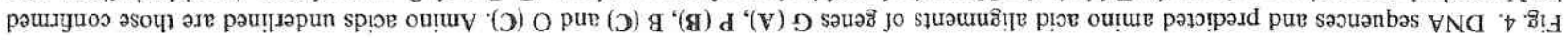

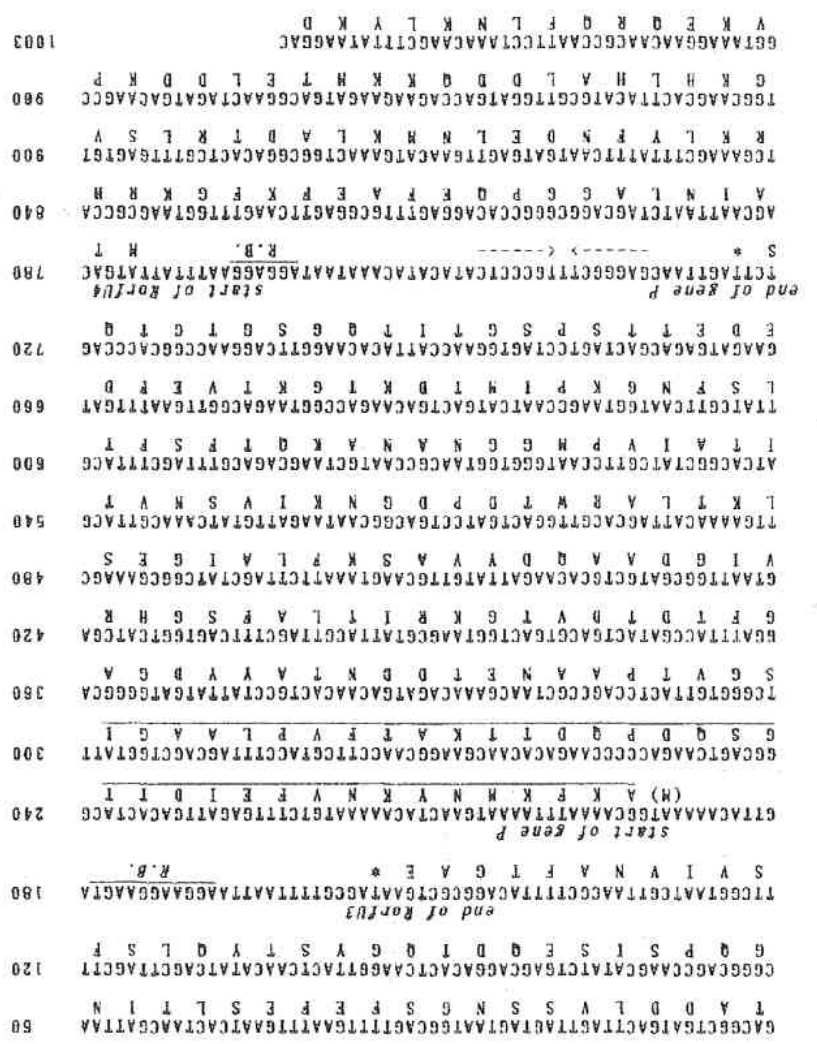

( g )

$6 b+1$

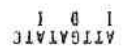

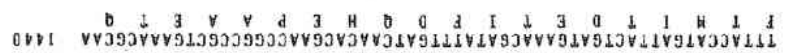
9. $N$ O

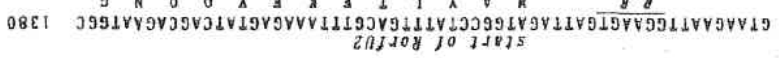

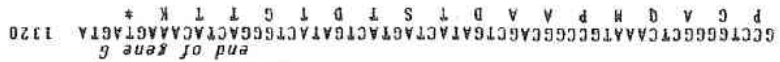

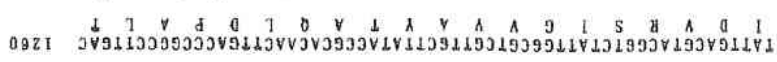

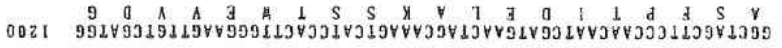

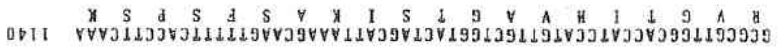

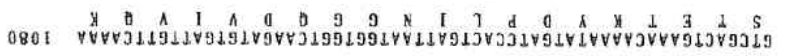

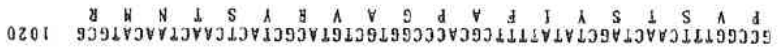

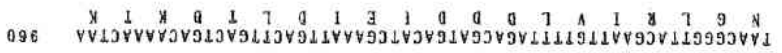

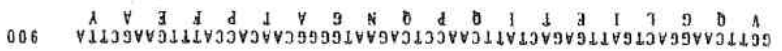

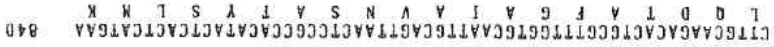

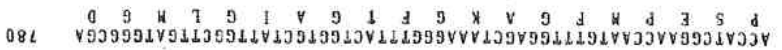

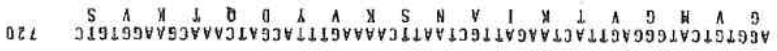

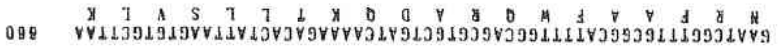

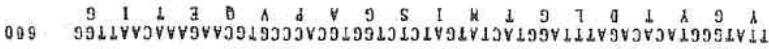

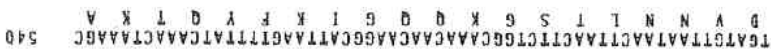

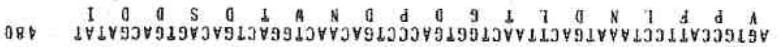

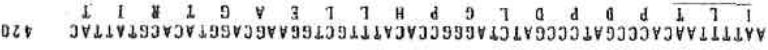

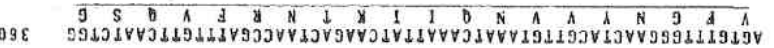
\begin{tabular}{lllllllllllll}
\hline 3 & $d$ & $A$ & $l$ & 7 & 0 & $S$ & 7 & $H$ & 1 & 3 & $V$ & $(k)$
\end{tabular}

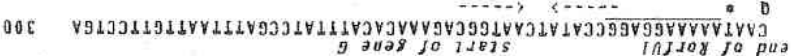

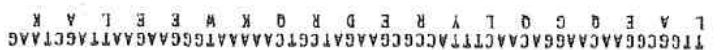

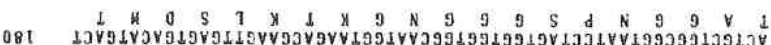

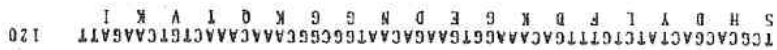
09

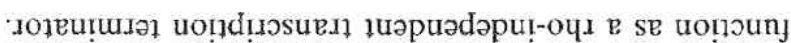

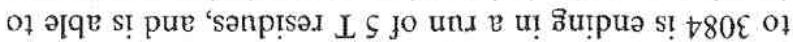

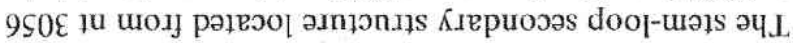
(Dt 9 !

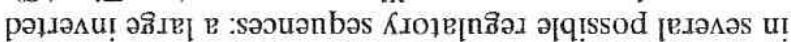

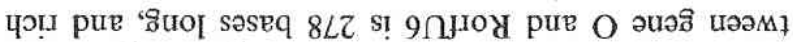

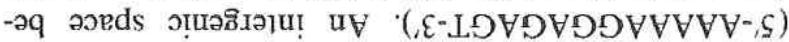

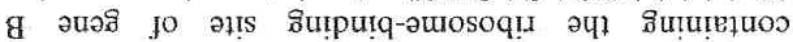

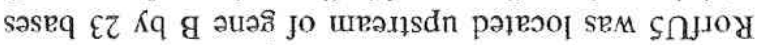

(VZ $81 \mathrm{I})$ GDVd

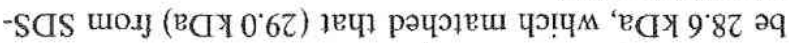

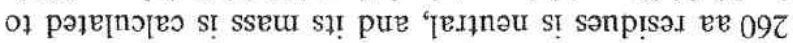

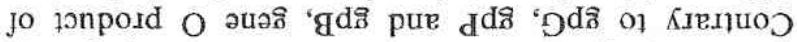

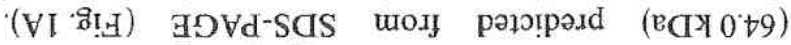

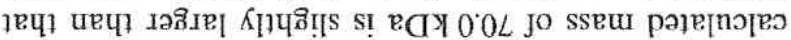

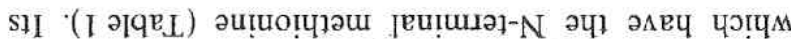

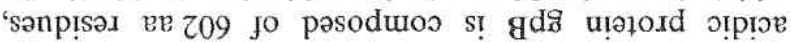

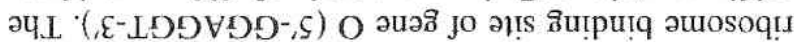

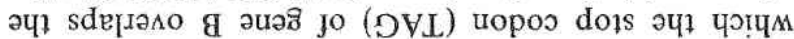

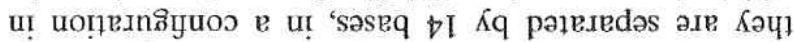

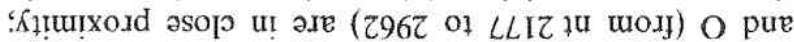

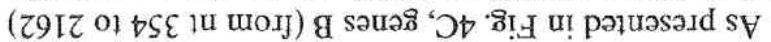

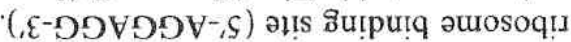

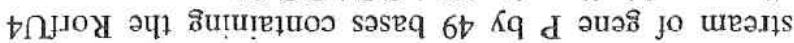

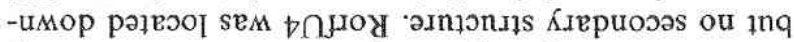

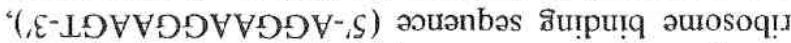

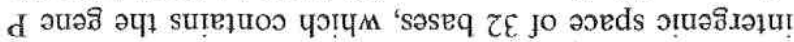

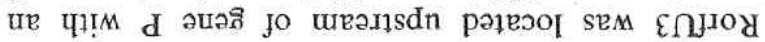

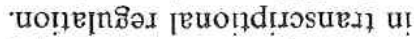

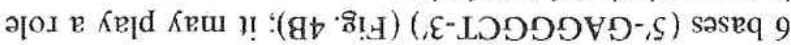




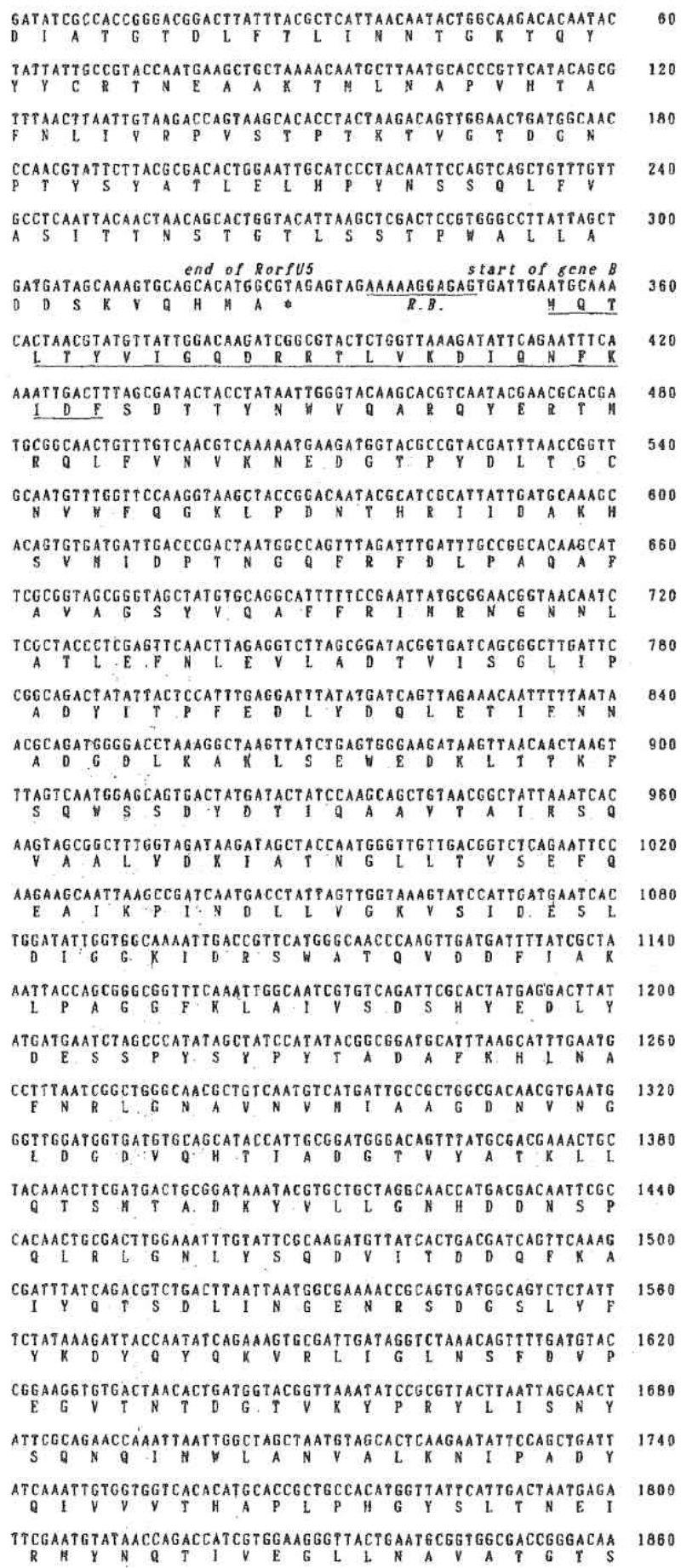

Sequences of the two promoter sequences are similar to those of $E$. coli: for -35 region, 5'-TTGAAA-3' from nt 3063 to 3068 and $5^{\prime}$-TTGCAC- $3^{\prime}$ from nt 3132 to 3137 , and for -10 region, 5'-TTTTAT-3' from nt 3086 to 3091 , and 5'-GATAGT-3' from nt 3155 to 3160 . 320

(1)

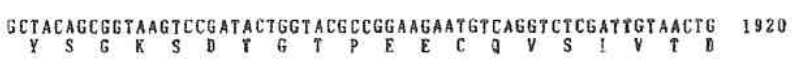
ACTATAATCCGCAAGgGCCACGACCAATCGCCGgCTTITTCGgCGgGCAYGITCATCAAG 1980 $Y$
N P ACATTATCAAGCCATTGGATCACTTTACGAACTGCETCGTACTAGCGGACGCCAATACTG 2040

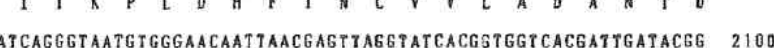

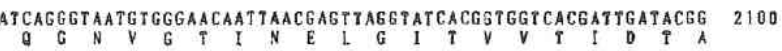
CCAACCGTAAGGTGACATTGAACGGACTAGGTCGgGCAACTGATCGTCAATITACTTAC? 2160 Start Of gene 0
AGGAGGTGATTTAAATATGGCAAATATAGTPGATAAACTAATCAGATTGGACGTAAGAC 2220

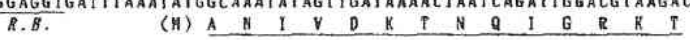
GACGGAGCTAGCTGCTAACATGATTCCAGCCTCAATTEAGAATAATGGTTTGATGGCCCC 2280 I E L A A N A I P A S I A N N G L R A P

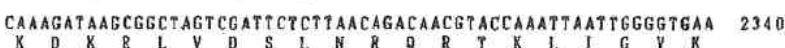
ATCAGTCAATGACTTGGACCAGGATTCTATTCGGGTGTGTGATGCTCAAAGATGTGCC 2400 AATAATCGATGGATTAACGGGATATAATGAATGGTTTATTGAAGTTAGTAAGACAGTCAC 2400 $\begin{array}{llllllllllll}I & I & G & L & T \\ T\end{array}$

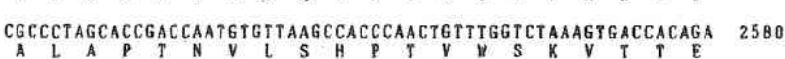
AaCCATTTTGTGGGCCGGATCGGCTGATTTGgCAGTAGgCACTAAATTAACATTGGTAGA 2640 $\begin{array}{llllllllllllllllllll}T & I & L & \text { N } & A & G & S & A & \text { O } & \text { L } & A & V & G & T & \mathbb{K} & \mathrm{L} & \mathrm{T} & \mathrm{L} & \mathrm{V} & \mathrm{D}\end{array}$ D A Y N Y D G G I V N Y Y Y F D G V S N S S 2700 CGCTCGCTTGCAGGCTTCACGAGCCGATGCACTGACAGGGGTACCACCTTACTTGTATTS 2760 GGACGGCACAAACATGTCTAATACGCTTAGTGATACAGTACTCAACATGGAATTCTTTGA 2820 AGCATACTTGGaGaAgGTAGACAATACCCATCTTAAATTCTCCAGCrTTAaCCACATCGT 2800 TGCCAATTTGGCCAAAGTACCGCTGTCPATAACACGGGCAACGGTGACTTCATGATTTC 2940 $A$ N $L A$ O G T A Y Y Y T G A G D F A I S end of sease 0

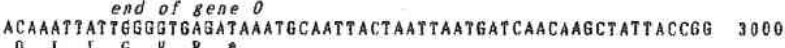

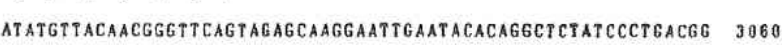

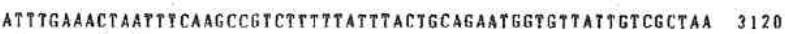

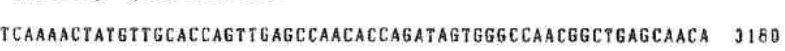

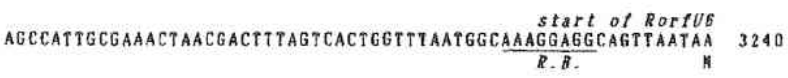
TGCTTGATTTGTTACTGTGGTAAAGGATTGCGGGTGTAGCCTIGATGAGATTACAGCGT 3300 CCGCAAGTAATTGTGTAGTGTCTGGTCAGATCACPAAAGATGATTATAAGACGATTACTG 3360 GTGAAGACTATGTgGCGTRACCGATATAGGACTCGTGTTGgCTGCGgTGATTAATGATC 3420 AACACTGGaCGCCGCCACACTACATCATGGGTTATCAGCTAGGTGAGTGgGCGTCGATTG 3480 AACACTGGACGCCECCACACTACATCATGGGTPATCAGCTAGGTGAGTGGG CGTCGATTG 3480 CGACAATCGTGATTTTTGTGrCCGGCCTAATCGTGGGTATTGTACGGATAGGCGTGATTA 3540 ACCCTGCACATATTGCAAACGAAACTTGCAGCATTCGATTGATCGGCTGACTGCCAAGA 3600

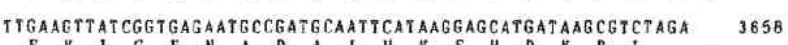

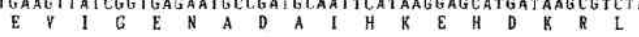

\section{Conclusions}

In this study, we characterized the capsid proteins of bacteriophage $\phi$ gle induced from Lactobacillus strain Gle, and determined structural genes encoding the 4 . 
TABLE 2

Genes encoding the major capsid proteins of $\phi \mathrm{gle}$ particle

\begin{tabular}{|c|c|c|c|c|c|}
\hline \multirow[t]{2}{*}{ Gene } & \multirow[t]{2}{*}{ Ribosome binding sequence ${ }^{\mathrm{a}}$} & \multicolumn{4}{|c|}{ Gene product ${ }^{b}$} \\
\hline & & Protein & AA & $\begin{array}{l}\text { MW } \\
\left(\times 10^{-3}\right)\end{array}$ & $\mathrm{p} I$ \\
\hline B & AaAAAGGAGag tgattgaATG & $\mathrm{gpB}$ & 602 & 70.0 & 4.75 \\
\hline G & AaAAAGGAGGc--catatcaATG & $\mathrm{gpG}$ & 350 & 37.5 & 4.85 \\
\hline $\mathrm{O}$ & tactAGGAGGT-gatttaaatATG & $\mathrm{gpO}$ & 260 & 28.5 & 6.35 \\
\hline $\mathrm{P}$ & AGgAAGGAaGTagttacaaaaATG & $\mathrm{gpP}$ & 177 & 18.7 & 4.70 \\
\hline 16 S RNA & AGAAAGGAGGT & & & & \\
\hline
\end{tabular}

a The sequence of Lactococcus 16s rRNA is from Ludwig et al. (1985). Capital letters indicate the nucleotides identical to those of 16s rRNA. Dashes represent gaps inserted to align nucleotides for maximal homology. ATG, starting codon.

${ }^{b} \mathrm{AA}$, number of amino acid residue (for gpG, gpO, and gpP, N-terminal methionine is omitted); MW, molecular weight calculated from DNA sequence; $\mathrm{p} l$, isoelectric point predicted from DNA sequence.

major capsid proteins gpB, gpG, gpO and gpP. Several properties of genes $\mathrm{G}, \mathrm{P}, \mathrm{B}$ and $\mathrm{O}$ are summarized in Table 2.

Information on phage capsid proteins of lactic acid bacteriophage is still scarce (Relano et al. 1987), and a few sequences are available at present: (i) in Lactobacillus temperate phage mv4, as well as virulent phage LL-H (Vasala et al., 1993), a major capsid protein g34, a capsid protein $\mathrm{g} 20$, and three minor capsid proteins (ORF-4, ORF-5, and ORF-6): (ii) in Lactococcus temperate phage Tuc2009 (Arendt et al., 1994), two minor capsid proteins (mp1 and mp2): (iii) in Lactococcus phage F4-1 (Chung et al., 1991), a major capsid protein MCP, and three minor capsid proteins (p35, p11 and p9.5). The 4 capsid proteins of $\phi$ gle identified in this study have no significant homology with those of mv4, LL-H, Tuc2009 or F4-1, in addition to coliphage lambda (Sanger et al., 1982).

The two $\phi$ gle proteins, gpG and gpP, resemble tail sheath and tube proteins of P2 (Temple et al., 1991) and T4 (Arisaka et al., 1988) in size and $\mathrm{p} I$. The tail sheath proteins of $F_{1}(\mathrm{P} 2)$ and gp18 (T4) are estimated to be acidic with a $\mathrm{p} I$ point of 4.85 and 4.79 , respectively, and the tail tube proteins of $F_{11}(\mathrm{P} 2)$ and gp19 (T4) are also acidic with a $\mathrm{pI}$ point of 4.85 and 4.51 , respectively. However, they are clearly different in amino acid sequences, and have no homology in the secondary structures estimated by a method of Chou and Fasman (1978).

Our recent sequencing results on $\phi$ gle DNA have shown that (i) the DNA region from gene $G$ to gene $O$ of approximately $14 \mathrm{~kb}$ contains many ORFs which are considerably compact, and probably encode the 16 minor phage structural proteins, in addition to the four major proteins (this study), suggesting that this region forms an operon for phage head/tail proteins (unpublished data), and (ii) following gene $\mathrm{O}$, there are a few ORFs, one of which is RorfU6 (see Fig. 4C); these ORFs are located in an approximately $2.5 \mathrm{~kb}$ region, and probably form another operon (referred to as Lysis operon), which is involved in disruption of the bacterial cell envelope (unpublished data). The possible regulatory structures of stem-loop and promoter sequences found between gene $\mathrm{G}$ and RorfU6 (see above) might function as a terminator of the head/tail operon, and promotor(s) for the lysis operon, respectively.

Unfortunately, $\phi$ gle forms no plaques on the indicator strains used in this study, as previously reported in many other temperate phages of lactic acid bacteria (Teuber and Lembke, 1983). We are now attempting to isolate a $\phi$ gle-cured strain supporting plaque formation with $\phi \mathrm{gle}$, although there remains a possibility that $\phi g l e$ is a defective phage.

Further studies on genome structure, gene functions and molecular taxonomy of phage $\phi g l e$ are in progress.

\section{Acknowledgements}

We thank Dr. H. Kusaoke (Fukui, Japan) for Nterminal amino acid sequencing, and Drs. Y. Masamune (Kanazawa, Japan), R. Hosono (Kanazawa, Japan), and F. Arisaka (Tokyo, Japan) for encouragement and support.

\section{References}

Arendt, E.K., Daly, C., Fitzgerald, G.F. and van de Guchte, M. (1994) Molecular characterization of Lactococcal bacteriophage Tuc2009 and identification and analysis of genes encoding lysin, a putative holin, and two structural proteins. Appl. Environ. Microbiol. 60, 1875-1883.

Arisaka, F., Ishimoto, L., Kassavetis, G., Kumazaki, T. and Ishii, S.-I. (1988) Nucleotide sequence of the tail tube structural gene of bacteriophage T4. J. Virol. 62, 882-886.

Ben-Bassat, A. and Bauer, K. (1987) Amino-terminal procession of proteins. Nature (London) 326, 315.

Campbell, A. (1994) Comparative molecular biology of lambdoid phages. Annu. Rev. Microbiol. 48, 193-222.

Chou, P.Y. and Fasman, G.D. (1978) Empirical prediction of protein conformation. Annu. Rev. Biochem. 47, 251-276.

Chung, D.K., Kim, J.H. and Batt, C.A. (1991) Cloning and nucleotide 
sequence of the major capsid protein from Lactococcus lactis ssp. cremoris bactcriophage F4-1. Gene 101, 121-125.

Davidson, B.E., Powell, I.B. and Hillier, A.J. (1990) Temperate bacteriophages and lysogeny in lactic acid bacteria. FEMS Microbiol. Rev., 87, 79-90.

Georgopoulos, C., Tilly, K. and Casjens, S. (1983) Lambdoid phage head assembly. In: Hendrix, R.W., Roberts, J.W., Stahl, F.W. and Weisberg, R.A. (Eds.), Lambda II. American Society for Microbiology. Washington, DC, pp. 279-304.

Hosono, R., Hekimi, S., Kamiya, Y., Sassa, T., Murakami, S., Nishiwaki, K., Miwa, J., Taketo, A. and Kodaira, K.-I. (1992) The unc-18 gene encodes a novel protein affecting the kinetics of acetylcholine metabolism in the nematode Caenorhabditis elegans. J. Neurochem. 58, 1517-1525.

Kim, J.H. and Batt, C.A. (1991) Nucleotide sequence and deletion analysis of a gene coding for a structural protein of Lactococcus lactis bacteriophage F4-1. Food Microbiol. 8, 27-36.

Kodaira, K.-I. and Taketo, A. (1984) Function and structure of microvirid phage $\alpha 3$ genome: I. Electrophoretic characterization of proteins encoded by wild-type phages. Biochim. Biophys. Acta 788, 333-338.

Kodaira, K.-I., Nakano, K., Okada, S. and Taketo, A. (1992) Nucleotide sequence of the genome of the bacteriophage $\alpha 3$ : interrelationship of the genome structure and the gene products with those of the pages, $\phi \times 174, G 4$, and $\phi K$. Biochim. Biophys. Acta 1130, 277-288.

Kodaira, K.-I., Oki, M., Taketo, A., Yasukawa, H. and Masamune, Y. (1994a) Determination of the single stranded origin of Shigella sonnei plasmid pKYM. Biochim. Biophys. Acta 1260, 183-190.

Kodaira, K.-I., Godson, G.N. and Taketo, A. (1994b) Comparative studies of the minus origin mutants of Escherichia coli spherical single-stranded DNA phages. Biochim. Biophys. Acta 1260, 191-199.

Lillehaug, D. and Birkeland, N.K. (1993) Characterization of genetic elements required for site-specific integration of the temperate lactococcal bacteriophage $\phi \mathrm{LC} 3$ and construction of integrationnegative $\phi$ LC3 mutants. J. Bacteriol. 175, 1745-1755.

Ludwig, W., Seewaldt, E., Klipper-Balz, R., Schleiffer, K.H., Magrum, L., Woese, C.R., Fox, G.E. and Stackebrandt, E. (1985) The phylogenetic position of Streptococcus and Enterococcus. J. Gen. Microbiol. 131, 543-551.

Nakashima, Y., Ikeda, H., Kakita, Y., Miake, F. and Watanabe, K. (1994) Restriction map of the genomic DNA of Lactobacillus casei bacteriophage PL-1 and nucleotide sequence of its cohesive singlestranded ends. J. Gen. Virol. 75, 2537-2541.

Okada, S., Daengsubha, W., Uchida, T., Ohara, N. and Kozaka, M. (1986) Flora of lactic acid bacteria in Miang produced in northern Thailand. J. Gen. Microbiol. 32, 57-65.
Pouwels, P.H. and Lee, R.J. (1993) Genetics of lactobacilli: plasmid and gene expression. Antonie van Leeuwenhoek 64, 85-107.

Raya, R.R., Kleeman, E.G., Luchansky, J.B. and Klaenhanmmer, T.R. (1989) Characterization of the temperate bacteriophage dadh and plasmid transduction in Lactobacillus acidophilus ADH. Appl. Environ. Microbiol. 55, 2206-2213.

Raya, R.R. and Klaenhammer, T.R. (1992) High-frequency plasmid transduction by Lactobacillus gasseri bacteriophage $\phi$ adh. Appl. Environ. Microbiol. 58, 187-193.

Relano, P., Mata, M., Bonneau, M. and Ritzenthaler, P. (1987) Molecular characterization and comparison of 38 virulent and temperate bacteriophages of Streptococcus lactis. J. Gen. Microbiol. 133, 3053-3063.

Sanger, F., Nicklen, S. and Coulson, A.R. (1977) DNA sequencing with chain-terminating inhibitors. Proc. Natl. Acad. Sci. USA 71, 5463-5467.

Sanger, F., Coulson, A.R., Hill, D.F. and Petersen, G.B. (1982) Nucleotide sequence of bacteriophage 2. DNA. J. Mol. Biol. $162,729-773$.

Sambrook, J., Fritsch, E.F. and Maniatis, T. (1989) Molecular Cloning. A Laboratory Manual, 2nd ed. Cold Spring Harbor Laboratory, Cold Spring Harbor, NY.

Schouler, C., Ehrlich, S.D. and Chopin, M.-C. (1994) Sequence and organization of the lactococcal prolate-headed bIL67 phage genome. Microbiology 140, 3061-3069.

Shimizu-Kadota, M. and Tsuchida, N. (1984) Physical mapping of the virion and prophage DNAs of a temperate Lactobacillus phage $\phi$ FSW. J. Gen. Microbiol. 130, 423-430.

Taketo, A. (1988) DNA transfection of Escherichia coli by electroporation. Biochim. Biophys. Acta 949, 318-324.

Temple, L.M., Forsburg, S.L., Calendar, R. and Christie, G.E. (1991) Nucleotide sequence of the genes encoding the major tail sheath and tail tube proteins of bacteriophage P2. Virology 181, 353-358.

Terzaghi, B.E. and Sandine, W.E. (1975) Improved medium for lactic streptococci and their bacteriophages. Appl. Microbiol. 29, 807-813.

Teuber, M. and Lembke, J. (1983) The bacteriophages of lactic acid bacteria with emphasis on genetic aspects of group $\mathrm{N}$ lactic streptococci. Antonie van Leeuwenhoek 49, 283-295.

Tomoda, A., Kodaira, K.-I., Taketo, A., Tanimoto, K. and Yoneyama, Y. (1984) Isolation of human erythrocyte membrane in glucose solution. Anal. Biochem. 140, 386-390.

Vasala, A., Dupont, L., Baumann, M., Ritzenthaler, P. and Alatossava, T. (1993) Molecular comparison of the structural proteins encoding gene clusters of two related Lactobacillus delbrueckii bacteriophages. J. Virol. 67, 3061-3068.

Yamamoto, K.R., Alberts, B.M., Benzinger, R., Lawhorne, L. and Treiber, G. (1970) Rapid bacteriophage sedimentation in the presence of polyethylene glycol and its application to large-scale virus purification. Virology 40, 737-744. 